\title{
SIMULATION MODEL OF CONTAMINATION THREAT ASSESSMENT IN WATER NETWORK USING THE EPANET SOFTWARE
}

\author{
MODEL SYMULACJI ZAGROŻENIA ZANIECZYSZCZENIAMI \\ W SIECI WODOCIĄGOWEJ Z UŻYCIEM PROGRAMU EPANET
}

\begin{abstract}
The aim of this study is to assess the risk of failure of group water network in case of raw water contamination. The analysis was based on qualitative simulation performed in hydraulic water network model developed in the EPANET software. It was focused on the quantitative description of the consequences of chemically contaminated water. The methodology of risk assessment relies in determining the consequences of the supply water containing contamination threatening the health and lives of water consumers. The research methodology is as follows: development of a hydraulic model of the water pipeline and it's hydraulic verification, computer simulations of contamination propagation, calculating the dose delivered to the $i$-th section of the water supply system supplying water to $\mathrm{N}_{\mathrm{i}}$ recipients and the mass of a substance that enters the body $l_{i}$. The simulation results indicate the spread of contamination that after $24 \mathrm{~h}$ covered most of the area supplied with water. The load delivered to the resident obtaining water from the $i$-th section of the water supply network, $L_{i} / N_{i}$, was up to $18 \mathrm{~g} \cdot \mathrm{d}^{-1}$, at least $15 \mathrm{~g} \cdot \mathrm{d}^{-1}$ was received by $34.9 \%$ of the population, $10-15 \mathrm{~g} \cdot \mathrm{d}^{-1}$ by $12.5 \%$ of the residents, $5-10 \mathrm{~g} \cdot \mathrm{d}^{-1}$ by $10.7 \%$ of the residents, $0-5 \mathrm{~g} \cdot \mathrm{d}^{-1}$ by $41.7 \%$ of the residents and uncontaminated water was delivered to only $13.3 \%$ of the consumers. The dose taken by the statistical consumer (calculated as for adults) 1 is up to $0.8 \mathrm{~g}$ for $L_{i} / N_{i}=18 \mathrm{~g} \cdot \mathrm{d}^{-1}$ and is proportional to $L_{i} / N_{i}$.
\end{abstract}

Keywords: water network, contamination, hazard assessment

\section{Introduction}

The main task of water distribution subsystems is to meet the needs for water supply, at the appropriate pressure and of suitable quality and quantity. Water supply systems belong to the critical infrastructure, fulfilling one of the key roles for the quality and safety of human life. Due to their spatial extent and the high degree of complexity water supply systems are particularly vulnerable to the occurrence of adverse incidental events, of which particularly dangerous are events resulting from the delivery of water with quality threatening consumer's health and lives. Critical failures are related to the difficulties in supplying water to a large number of water consumers. For this type of undesirable events

\footnotetext{
${ }^{1}$ Department of Water Supply and Sewerage Systems, Faculty of Civil and Environmental Engineering, Rzeszow University of Technology, al. Powstańców Warszawy 6, 35-959 Rzeszów, Poland, phone +48 178651703 , fax +48 178651175 , email: astud@ @rz.edu.pl

*Corresponding author: kpiet@prz.edu.pl
} 
we can include [1-8]: water contamination in the water intake, water intakes failure, failures of water treatment equipment, failure of pumping stations and water pumping, damage of strategic main and transit pipelines or a possible terrorist acts. Previous studies conducted in different operating water supply systems pay attention to the significant effect of the potential safety loss resulting from the failure [9-14]. Identification of the dependence between the damage and losses arising from failure is an important aspect of everyday operation water supply system, examples of such studies taking into account the analysis of aforementioned parameters of failure, are among others [15-21].

Contamination of tap water may occur at any of water supply system elements. In the works $[22,23]$ contaminations in the water supply network were analyzed, usually they have local coverage. In practice, the most frequent cases of global contamination of water supply network are contaminations resulting from the contamination of water source or irregularities in the process of water treatment [24]. While assessing the water consumer risk resulting from the consumption of chemically contaminated water three parameters is crucial - time from the occurrence of contamination to the water delivery to the consumer, and the concentration and load of contamination taken by the consumer from the tap water.

A well-known tool for the analysis of water supply network, both in terms of quantity and quality, is the EPANET software [25-27]. It is successfully used for qualitative analysis of disinfectants and naturally occurring in water compounds $[5,6]$.

The aim of this study is to assess the risk of failure of group water network in case of raw water contamination. The analysis was based on qualitative simulation performed in hydraulic water network model developed in the EPANET software. It was focused on the quantitative description of the consequences of chemically contaminated water.

\section{The research methodology}

The methodology of risk assessment relies in determining the consequences of the supply water containing contamination threatening the health and lives of water consumers. The main factors influencing the threat are time from the occurrence of contamination to its occurrence at water recipient, load of contamination and its maximum concentration $[28,29]$. In this paper we omitted concentration changes resulting from the kinetics of chemical reactions with naturally occurring in tap water compounds, delivered in the water treatment and compounds remaining in the sediments present in the water supply network, since these factors are individual for each water pipeline.

In case of chemicals that do not induce genotoxic effects, the threshold value below which even with long-term exposure to them the harmful health effects do not appear, is determined [30]. The threshold values are characterized by the harmful effect when the body's physiological reserves are depleted and they take into account the ability to regenerate body $[28,31]$.

The dose delivered to the $i$-th section of the water supply system supplying water to $N_{i}$ recipients can be determined according to the relation:

$$
L_{i}=\sum_{t=0}^{t} c_{i t} Q_{i t} \Delta t
$$

where $L_{i}$ is the load of substance delivered to the recipient supplied from section $i$ [mg], $c_{i t}$ is the concentration of contamination indicator in water in time $t\left[\mathrm{mg} \cdot \mathrm{dm}^{-3}\right], Q_{i t}$ is water demand in section $i$ in time $t\left[\mathrm{~m}^{3} \cdot \mathrm{s}^{-1}\right], \Delta t$ is exposure time [s]. 
Weight of tap water taken from the tube and is expressed by the equation:

$$
l_{i}=\frac{q \sum_{t=0}^{t} c_{i} \Delta t}{B t}
$$

where $l$ is the mass of a substance that enters the body $\left[\mathrm{mg} \cdot \mathrm{kg}^{-1} \cdot \mathrm{d}^{-1}\right], q$ is the volume of consumed water $\left[\mathrm{dm}^{3} \cdot \mathrm{d}^{-1}\right],\left(2 \mathrm{dm}^{3}\right.$ - adults, $1 \mathrm{dm}^{3}$ - children, $0.75 \mathrm{dm}^{3}$ - infants + which is $2-0.75 \%$ of the average daily water consumption), $t$ is duration of exposure [d], $B$ is the average weight of the human body during exposure $[\mathrm{kg}],(60 \mathrm{~kg}$ - adults, $10 \mathrm{~kg}$ - children, $5 \mathrm{~kg}$ - infants).

The risk of loss of health (life) of water consumer does not occur when $l_{i}$ does not exceed the tolerable daily intake [29]:

$$
l_{0}=N O A E L / S F
$$

or

$$
l_{0}=L O A E L / S F
$$

where:

- NOAEL (No Observed Adverse Effect Level) is the highest dose level at which statistically significant increase in the frequency of side effects among the exposed people compared to the unexposed people is not observed;

- LOAEL (Lowest Observed Adverse Effect Level) is the lowest level of the observed harmful effect,

- $\quad S F$ (Safety Factor) - the product of the following factors:

- factor taking into account species differences,

- factor taking into account interspecies differences,

- factor taking into account the appropriateness of the study,

- factor taking into account the nature of the effect.

Each of these factors is within the range of 1 to 10 , total SF value can reach $10^{4}$.

It is assumed, that the risk of life loss occurs when the lowest published lethal dose $-l_{d}$ is reached.

Thus the most important is the concentration of the toxic compound $c$ and its variability over time in water and the time of recipient exposure to contaminated water. The concentration is the result of the structure of water pipeline, and, in particular, of the number of independent water supply sources, the existence of retention capacity in the water supply network, water supply network spatial structure and variability of water demand in both daily and hourly cycle and it results directly from the hydraulics of system $[22,26,32]$ and are defined through reliability and safety of system functioning [33, 34].

The research methodology is as follows:

- development of a hydraulic model of the water pipeline,

- $\quad$ hydraulic calibration of the model,

- computer simulations of contamination propagation.

\section{Description of the object}

The methodology presented in point 1 for the group water pipeline supplying water to about 14000 inhabitants was used. The analysed water pipeline is young, the beginnings of the construction of water supply infrastructure fall in the second half of the 80's of the last century, the first section of the network was made in 1987. 
The hydraulic model was developed in the EPANET 2.0 based on the data obtained from the water supply network explorer. The water supply system is provided with water from the underground intake, after treatment water is stored in the clean water tanks and then pumped to the water network. In Figure 1 a scheme of the water supply network made in the EPANET, with marked basic network elements, is shown. The model includes the treated water tanks ( 3 tanks, each with a capacity of approx. $300 \mathrm{~m}^{3}$ ), the pumping station, the water network tanks and 406 distribution water pipes. The pumping stations are equipped with the pumping sets controlled by the constant pressure algorithm which allows them to pump the water capacity equal to the water demand.

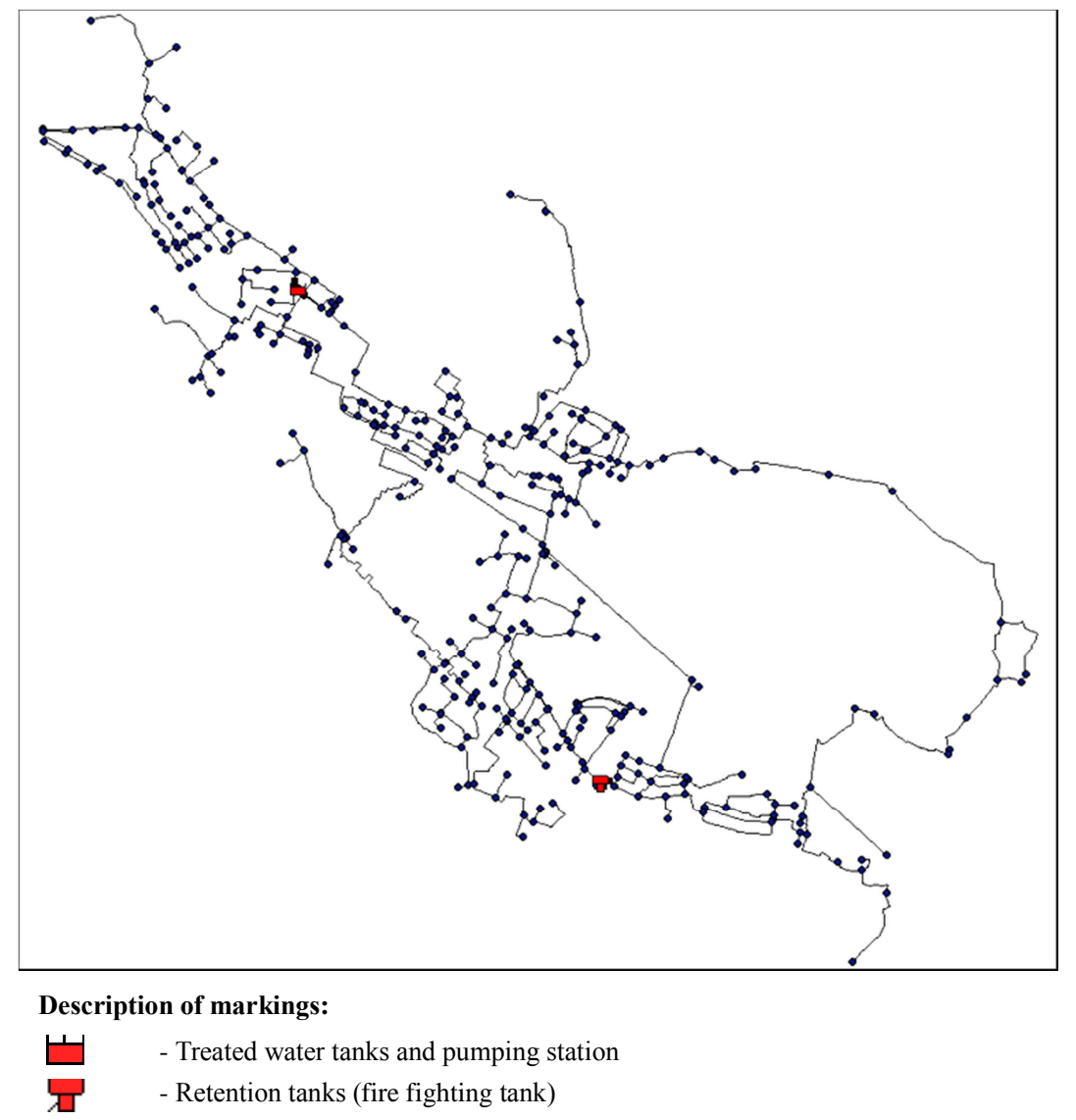

Fig. 1. The water supply network scheme in the EPANET software

The water pipeline supplies water to inhabitants of a town and 3 neighbouring villages, in the urban-rural municipality the water supply network provides water to $61 \%$ of the total population. The number of people using the water supply network is 13,689 inhabitants (of which 10,421 are residents of the town). The structure of water network can be seen as a mixed. It consists of a number of rings, with branching segments at the ends of the network. It is constructed of PE (39.5\%), PVC (59.8\%) and cast iron (0.7\%). The range of 
nominal diameters is between ND $80 \mathrm{~mm}$ to ND $300 \mathrm{~mm}$, mainly ND $100 \mathrm{~mm}$ and ND $150 \mathrm{~mm}$. The total length of distribution pipelines is $93.1 \mathrm{~km}$.

In the southern part of the network there is a water retention tank with capacity $500 \mathrm{~m}^{3}$ which provides water only in case of fire fighting or during a large leak failure.

The following assumptions were made: the constant concentration of the contaminant in the treated water tanks was $10 \mathrm{mg} / \mathrm{dm}^{3}$. The spread of contamination over $24 \mathrm{~h}$ at every hour was simulated. Epanet enables to take into consideration diffusion (default diffusion coefficient for chlorine at $193 \mathrm{~K} \mathrm{D}=1.20 \cdot 10^{-5} \mathrm{~cm}^{2} / \mathrm{s}$ was applied). Also the program can use four different types of models to characterize mixing within storage tanks.

EPANET allows to apply 2 models of reactions kinetics occurring in the bulk flow and a model of wall reactions kinetics. Changes in concentration of the substance resulting from chemical reactions with the compounds contained in water were omitted. Consequently, the time of arrival of contamination to the receiver is the result of the flow path.

In the paper full mixing of the contaminant was assumed, therefore turbulent flow occurs inside the pipelines. Reynolds number Re is 55000 to 156000 in the pipelines from the pumping station and in main distributive pipes is 4600 to 163000 . The lowest flow velocities are in network endings (even less than $0.01 \mathrm{~m} / \mathrm{s}$ ) where $\mathrm{Re}<2000$, which is caused by using pipelines ND $80 \mathrm{~mm}$ according to fire regulations.

\section{The results and discussion}

Exemplary simulation results are shown in Figures 2-6, where red colour means contaminant concentration $c \geq 8 \mathrm{mg} \cdot \mathrm{dm}^{-3}$, orange $5 \leq c<8 \mathrm{mg} \cdot \mathrm{dm}^{-3}$, yellow $2.5 \leq c<5 \mathrm{mg} \cdot \mathrm{dm}^{-3}$ and light green $0.5 \leq \mathrm{c}<2.5 \mathrm{mg} \cdot \mathrm{dm}^{-3}$.

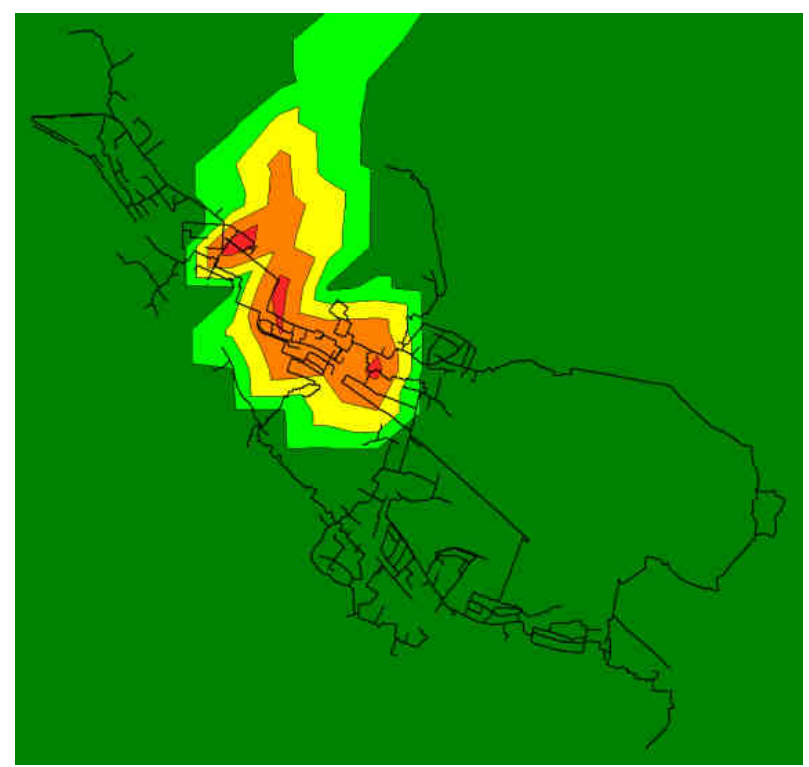

Fig. 2. Exemplary simulation results of the spread of contamination in the water supply system in the second hour of simulation 


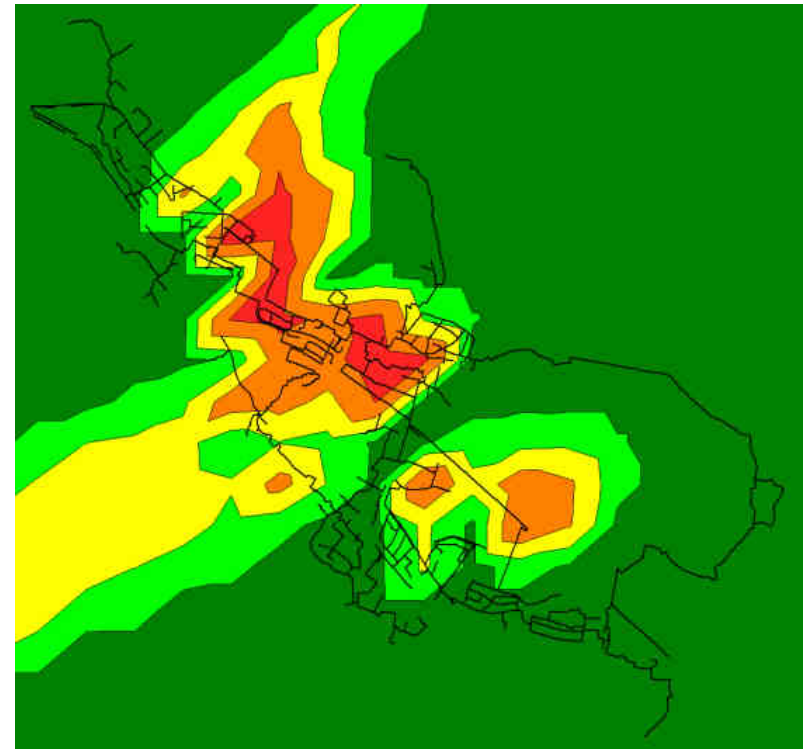

Fig. 3. Exemplary simulation results of the spread of contamination in the water supply system after $6 \mathrm{~h}$ from the start of simulation

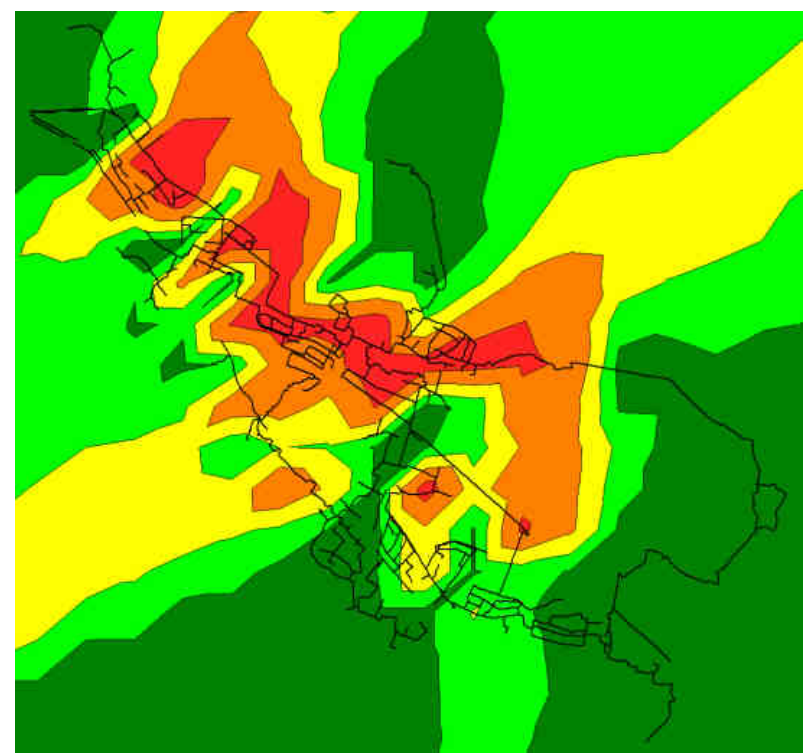

Fig. 4. Exemplary simulation results of the spread of contamination in the water supply system after $12 \mathrm{~h}$ from the start of simulation

The simulation results indicate the spread of contamination that after $24 \mathrm{~h}$ covered most of the area supplied with water. The load delivered to the resident obtaining water from the $i$-th section of the water supply network, $L_{i} / N_{i}$, was up to $18 \mathrm{~g} \cdot \mathrm{d}^{-1}$, at least 
$15 \mathrm{~g} \cdot \mathrm{d}^{-1}$ was received by $34.9 \%$ of the population, $10-15 \mathrm{~g} \cdot \mathrm{d}^{-1}$ by $12.5 \%$ of the residents, $5-10 \mathrm{~g} \cdot \mathrm{d}^{-1}$ by $10.7 \%$ of the residents, $0-5 \mathrm{~g} \cdot \mathrm{d}^{-1}$ by $41.7 \%$ of the residents and uncontaminated water was delivered to only $13.3 \%$ of the consumers. The dose taken by the statistical consumer (calculated as for adults) $\mathrm{l}_{\mathrm{i}}$ is up to $0.8 \mathrm{~g}$ for $L_{i} / N_{i}=18 \mathrm{~g} \cdot \mathrm{d}^{-1}$ and is proportional to $L_{i} / N_{i}$.

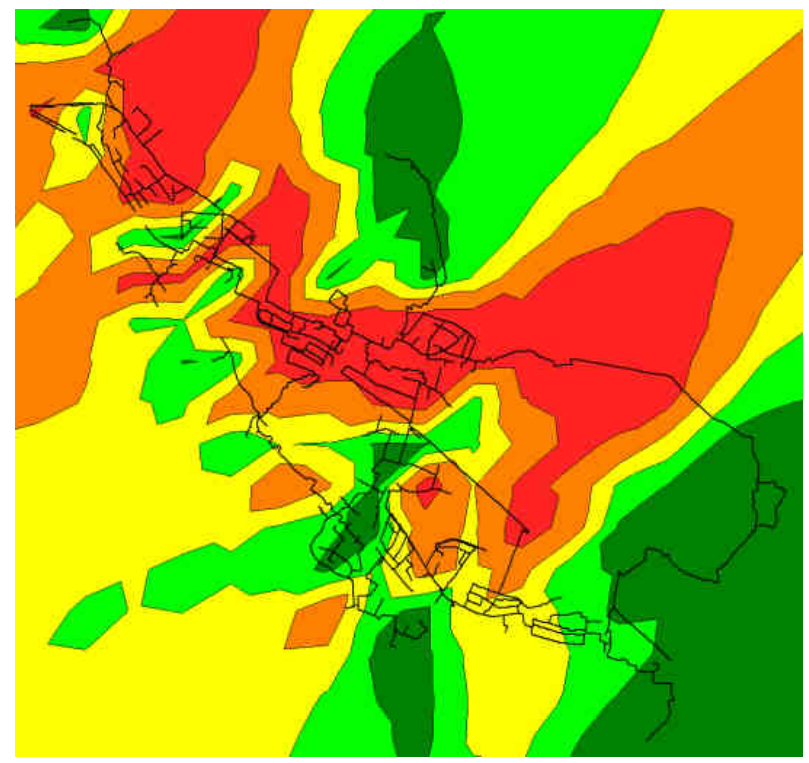

Fig. 5. Exemplary simulation results of the spread of contamination in the water supply system after $24 \mathrm{~h}$ from the start of simulation

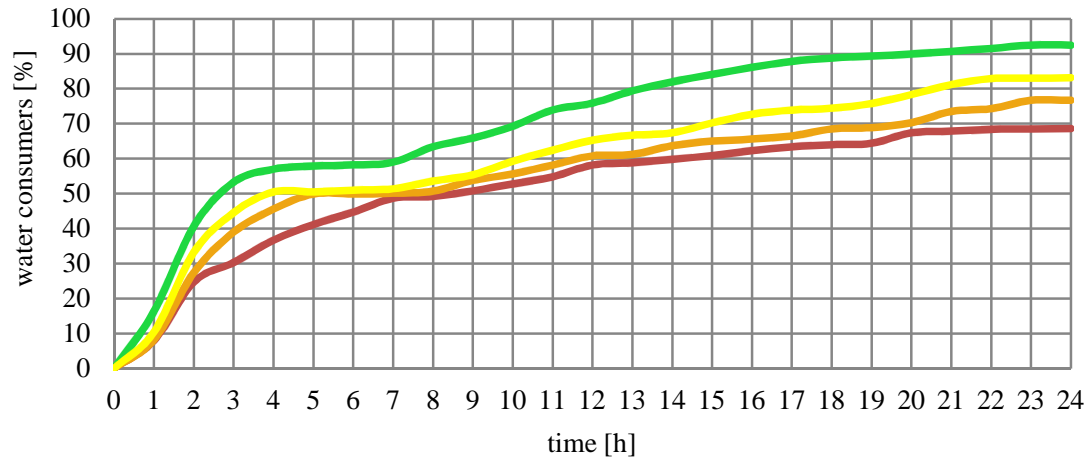

Fig. 6. Simulation results of the spread of contamination in the water supply system, red colour contaminant concentration $c \geq 8 \mathrm{mg} \cdot \mathrm{dm}^{-3}$, orange $5 \leq c<8 \mathrm{mg} \cdot \mathrm{dm}^{-3}$, yellow $2.5 \leq c<5 \mathrm{mg} \cdot \mathrm{dm}^{-3}$, light green $0.5 \leq c<2.5 \mathrm{mg} \cdot \mathrm{dm}^{-3}$ 


\section{Conclusions}

Variability of contamination concentrations of toxic substances and their propagation in water supply systems have the individual characteristics, in the literature there are not any research on their verification in the real water supply systems. Based on hydraulic models of water supply network the scenarios of the spread of harmful substances can be developed. The performed simulation shows how sensitive to contamination may be modern water supply systems in case of an accidental contamination. Especially important is a time of contamination propagation. The results show how very sensitive is the water supply system when delivered water is contaminated, especially with toxic substances.

For individual contamination, knowing the values of $l_{0}$ and $l_{d}$ and reaction kinetics model, using the presented method, the risk of loss of tap water consumers lives and health, the potential consequences of water contamination, the extent of contamination impact and the potential losses resulting from water contamination, can be easily determined.

Unfortunately water companies are usually not interested in creating hydraulic models because of high costs and workload, nevertheless models constitute the only way to test contamination propagation in water network, establish consumers risk and create emergency procedures.

\section{References}

[1] Deng Y, Jiang W, Sadiq R. Expert Syst Appl. 2011;38:571-578. DOI: 10.1016/j.eswa.2010.07.004.

[2] Abokifa AA, Yang YJ, Lo CS, Biswas P. Water Res. 2016;89:107-117. DOI: 10.1016/j.watres.2015.11.025.

[3] Hua P, Vasyukova E., Uhl W. Water Res. 2015;75:109-112. DOI: 10.1016/j.watres.2015.01.037.

[4] Kolasa-Wiecek A. Ecol Chem Eng S. 2010;17:363-371. http://tchie.uni.opole.pl/freeECE/ S_17_3/KolasaWiecek_17\%28S3\%29.pdf.

[5] Zimoch I, Lobos E. Environ Prot Eng. 2010;36:105-115. http://epe.pwr.wroc.p1/2010/zimoch_4-2010.pdf.

[6] Liua J, Chenb H, Yaob L, Weib Z, Loub L, Shanc Y, et al. J Hazard Mater. 2016;317:27-35. DOI: 10.1016/j.jhazmat.2016.05.048.

[7] Valis D, Zak L, Pokora O. P I Mech Eng O-J Ris. 2015;229:36-45. DOI: 10.1177/ 1748006X14547789.

[8] Diadovski I, Atanassova M, Simeonov V. Ecol Chem Eng S. 2011;18:319-332. http://tchie.uni.opole.pl/ freeECE/S_18_3/DiadovskiAtanassova_18\%28S3\%29.pdf.

[9] Vaabel J, Koppel T, Sarv L, Annus I. Procedia Eng. 2014;89:679-684. DOI: 10.1016/j.proeng.2014.11.494.

[10] Palleti VR, Narasimhan S, Rengaswamy R. Comput Aided Chem Eng. 2014;33:1447-1452. DOI: 10.1016/B978-0-444-63455-9.50076-3.

[11] Eliades DG, Lambrou TP, Panayiotou CG, Polycarpou MM. Procedia Eng. 2014;89:1089-1096. DOI: 10.1016/j.proeng.2014.11.229.

[12] Furnass WR, Mounce SR, Boxall JB. Environ Model Softw. 2013;40:78-87. DOI: 10.1016/j.envsoft.2012.07.012.

[13] Eliades DG, Stavrou D, Vrachimis SG, Panayiotou CG, Polycarpou MM. Procedia Eng. 2015;119:1429-1438. DOI: 10.1016/j.proeng.2015.08.1003.

[14] Oliker N, Ohar Z, Ostfeld A. Environ Model Softw. 2016;77:71-80. DOI: 10.1016/j.envsoft.2015.11.013.

[15] Sunela MI, Puust R. Procedia Eng. 2015;119:744-752. DOI: 10.1016/j.proeng.2015.08.928.

[16] Soldi D, Candelieri A, Archetti F. Procedia Eng. 2015;119:1259-1268. DOI: 10.1016/j.proeng.2015.08.990.

[17] Schwartz R, Lahav O, Ostfeld A. Water Res. 2014;63:271-284. DOI: 10.1016/j.watres.2014.06.030.

[18] Shuang Q, Zhang M, Yuan Y. Reliab Eng Syst Safe. 2014;124:132-141. DOI: 10.1016/j.ress.2013.12.002.

[19] Gheisi A, Naser G. Procedia Eng. 2014;89:326-332. DOI: 10.1016/j.proeng.2014.11.195.

[20] Rezaei H, Ryan B, Stoianov I. Procedia Eng. 2015;119:253-262. DOI: 10.1016/j.proeng.2015.08.883.

[21] Li XX, Wang HB, Hu XX, Hu C, Liao LF. Eng Fail Anal. 2016;60:166-175. DOI: 10.1016/j.engfailanal.2015.11.048.

[22] Pietrucha-Urbanik K. Eng Fail Anal 2015;57:137-142. DOI: 10.1016/j.engfailanal.2015.07.036.

[23] Craun GF, Calderon RL. Waterborne disease outbreaks caused by distribution systems deficiencies. J Am Water Works Ass. 2001;93:64-75. http://www.awwa.org/publications/journal-awwa/abstract/articleid/14423/ issueid/33533924.aspx?getfile=I|pers75apppcrlpersonify\serverfiles\dcdfiles $\backslash 14423$ \waternet.0054682.pdf. 
[24] Blokker M, Smeets P, Medema G. Procedia Eng. 2014;89:151-159. DOI: 10.1016/j.proeng.2014.11.171.

[25] Xin K, Tao T, Wang Y, Liu S. Front Environment Sci Eng. 2012;6:839-848. DOI: 10.1007/s11783-012-0409-8.

[26] Aminravan F, Sadiq R, Hoorfar M, Rodriguez MJ, Najjaran H. Expert Syst Appl. 2015;42:3813-3831. DOI: 10.1016/j.eswa.2014.11.014.

[27] Ondrejka Harbulakova V, Purcz P, Estokova A, Luptakova A, Repka M. Chem Eng Trans. 2015;43:2221-2226. DOI: 10.3303/CET1543371.

[28] Rasekh A, Brumbelow K. Environ Model Software. 2014;51:12-25. DOI: 10.1016/j.envsoft.2013.09.019.

[29] Rak JR. Environ Prot Eng. 2009;2:23-28. http://epe.pwr.wroc.pl/2009/Rak_2-2009b.pdf.

[30] Besner MC, Prévost M, Regli S. Water Res. 2011;45:961-979. DOI: 10.1016/j.watres.2010.10.035.

[31] Davis MJ, Janke R, Magnuson ML. Risk Anal. 2014;34:498-513. DOI: 10.1111/risa.12107.

[32] Liu S, Che H, Smith K, Chang T. J Environ Manage. 2015;154:13-21. DOI: 10.1016/j.jenvman.2015.02.023.

[33] Tchórzewska-Cieślak B, Pietrucha-Urbanik K, Urbanik M. Eksploat Niezawodn. 2016;18:254-259. DOI: 10.17531/ein.2016.2.13.

[34] Nowacka A, Wlodarczyk-Makula M, Tchorzewska-Cieslak B, Rak J. Desalin Water Treat. 2016;57:1297-1309. DOI: 10.1080/19443994.2015.1030108. 